\title{
Sometimes new does not mean safer
}

\section{Constantin-Dan Bordeianu}

Private Practice, Ploiesti, Prahova, Romania
This article was published in the following Dove Press journal:

Clinical Ophthalmology

4 January 2017

Number of times this article has been viewed

\section{Dear editor}

I was extremely interested in an article by Masuda et al, ${ }^{1}$ recently published in your Clinical Ophthalmology journal, especially after reading in the abstract that the phaco tip is the only surgical instrument required "for lens cleavage and removal". The authors assert that this new technique maintains a stable intraocular pressure during hydrodissection and lens removal, whereas the existing techniques induce anterior chamber instability because three instruments are successively inserted and withdrawn. However, the attached video contradicts these assertions, as the following were observed: (i) a second instrument is used to split the grooved nucleus, to chop the quarters, and to manipulate the fragments; (ii) in all, the authors used more than three instruments: cannula for saline or for ophthalmic viscoelastic device, phaco tip, chopper, and irrigation/aspiration cannula; and (iii) the wound leakage around the chopper is obvious. Given these conditions, how could the intraocular pressure be considered stable?

In my opinion, the suggested technique presents more risks than the classic methods do. The technique begins with cortex aspiration within the capsulorhexis area, using the phaco tip: this maneuver is not new. Then, cortex aspiration continues with the phaco tip inserted under the anterior capsule at 6 o'clock. This might be a novelty, but again, in my opinion, risks are involved: the aspiration mouth is large and wide bites of the attached cortex are aspirated. In the video, sometimes, the tissue did not come off easily, and forced tractions were evident: in case of small disinsertion of the inferior zonule, unobservable before surgery because usually it is not accompanied by irido-phacodonesis, these tractions could enlarge the disinsertion. The authors continue the cortex aspiration under the anterior capsule, with the phaco tip in such a position that one hole of the sleeve is oriented towards the undetached cortex, hoping that the theory of "irrigation dynamic pressure hydrodissection" is true.

Nothing in the video presentation attached to the article proves that this theory works; at no time was a hydrodissection wave observed. I rather believe that the repeated manipulations of the nucleus with the belly of the phaco tip during the anterior cortex aspiration loosened the adhesions of the soft cortex to the posterior capsule. Then, the lateral pushing/rotating movements with the phaco tip increased the loosening effect of a nucleus that remained too small in the bag; finally, as the adhesions with the anterior capsule have been eliminated together with the soft anterior cortex, nucleus rotation was obtained.

However, these forced movements of pushing/rotating the still adherent nucleus are far from the ideal phacoemulsification technique, in which the lens should not change its position in relation to the other components of the anterior pole: this is of particular importance, especially in cases with frail zonulae. In my work, I named the
Correspondence: Constantin-Dan

Bordeianu

Email bordmail3@yahoo.com
Clinical Ophthalmology 2017:I I |49-152

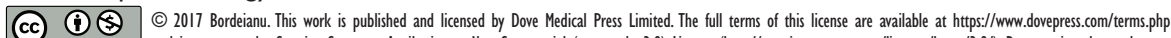
(c) ${ }_{\mathrm{BY}} \mathrm{NC}$ and incorporate the Creative Commons Attribution - Non Commercial (unported, v3.0) License (http://(creativecommons.org/licenses/by-nc/3.0/). By accessing the work you hereby accept the Terms. Non-commercial uses of the work are permitted without any further permission from Dove Medical Press Limited, provided the work is properly attributed. For permission hereby accept the Terms. Non-commercial uses of the work are permitted without any further permission from Dove Mercial use of this work, please see paragraphs 4.2 and 5 of our Terms (https://www.doveperss.com/terms.php).
for commercial 
ideal technique "isometric phacoemulsification"; 2 Sourdille and Poirer named it "no motion phaco". ${ }^{3}$ Of the terms used, I believe that "isometric" reflects better the idea than "no motion" does; besides the fact that the last terms appeared later in the field, one cannot define as "no motion" a technique that requires so many movements.

Overall, I believe that my technique is safer: after performing the "one drop staining technique" for the anterior capsule (an original approach), I place an anterior chamber maintainer, practice capsulorhexis with coaxial forceps under saline infusion and continue with classic hydrodissection, with several fluid waves correctly injected in different sites, alternating with pushes on the central nucleus. Next, I rotate the nucleus with two cystotomes placed in capsulorhexis area at 12 and 6: this mobilizes the central anterior cortex and indicates the hydrodelineation level. After hydrodelineation, I aspirate with the $10 \mathrm{~mL}$ glass syringe and $23 \mathrm{G}$ cannula the central cortex, and as much cortex as possible under the anterior capsule, above the hydrodelineation level, in the inferior and left sectors, in order to create space for the horizontal chopper (I am a right handed). Evidently, the bites through the cannula are smaller, and the risks connected with possible residual cortex adhesions that could pull the capsule equator in case of zonule frailness are diminished. I conclude the surgery with "isometric phacoemulsification", lens implantation, ophthalmic viscoelastic device evacuation, and wound hydration.

\section{Disclosure}

The author reports no conflicts of interest in this communication.

\section{References}

1. Masuda Y, Oki K, Iwaki H, Okamoto T, Tsuneoka H. Use of the phaco tip technique for lens cleavage and removal during cataract surgery. Clinical Ophthalmology. 2016;10:1925-1929.

2. Bordeianu CD. A new phacoemulsification technique meant to protect the relatively more fragile diathermic capsulorhexis rim. Abstract in: The 22nd ESCRS Congress, Paris, 2004. Dublin: ESCRS; 2004:122.

3. Sourdille P, Poirer C. Immobile movement concept enhances safety of bimanual microincision surgery. Ocular Surg News. 2007;25(20): $46-47$. 


\section{Authors' reply}

Yoichiro Masuda

Department of Ophthalmology, Jikei University Katsushika Medical Center, Tokyo, Japan

Correspondence: Yoichiro Masuda

Department of Ophthalmology, Jikei University Katsushika Medical

Center, 6-4I-2 Aoto, Katsushika-ku, Tokyo I25-8506, Japan

$\mathrm{Tel}+8 \mathrm{I} 336032$ III

Fax +81336907474

Email massuuu@gmail.com

\section{Dear editor}

We would like to thank Dr Bordeianu for his interest in our article. We would like to reply to his comments point by point. Our specific responses and the changes that we have made are described in the text that follows. The original comments made by Dr Bordeianu are marked "Q", while our responses are marked " $R$ ".

Q: A second instrument is used to split the grooved nucleus, to chop the quarters, and to manipulate the fragments. In all, the authors used more than three instruments: cannula for saline or for ophthalmic viscoelastic device, phaco tip, chopper, and irrigation/aspiration cannula.

R: Our surgical technique focuses on three parts of the cataract surgical process. These include 1) hydrodissection using a syringe and cannula, 2) nucleus phacoemulsification using the phaco tip, and 3) aspiration of cortex using the irrigation/aspiration tip (I/A tip). In all of these stages, we only use the phaco tip with support from the Shinkawabashi hook, which is used to divide the nucleus.

Q: The wound leakage around the chopper is obvious. Given these conditions, how could the intraocular pressure be considered stable?

$\mathrm{R}$ : Wound leakage at the paracentesis site is a normal part of any phacoemulsification surgical procedure, and thus, the leakage seen in the video is not considered to be a special event when using this technique. Our statement that the intraocular pressure (IOP) was considered to be stable is based on comparisons with the IOPs that are observed during conventional surgical methods, which usually require the insertion and removal into the anterior chamber of three different instruments.

Q: Then, cortex aspiration continues with the phaco tip inserted under the anterior capsule at 6 o'clock. This might be a novelty, but again, in my opinion, risks are involved; the aspiration mouth is large and wide bites of the attached cortex are aspirated.

R: Once again, we would like to emphasize that at this particular stage of the procedure, with the whole-lens in place and keeping the entire capsule stretched, aspirating under the capsulorhexis edge does not vacuum or engage the capsule. The aspiration port never becomes fully occluded, and the Dewey phaco tip provides additional safety because of its smoothly polished edge.

Q: In the video, sometimes, the tissue did not come off easily, and forced tractions were evident; in case of small disinsertion of the inferior zonule, unobservable before surgery because usually it is not accompanied by irido-phacodonesis, these tractions could enlarge the disinsertion.

$\mathrm{R}$ : When using the phaco tip for the cortical removal prior to the nucleus removal, we believe that the traction did not exceed that which occurs during the original cortical removal when using IA.

Q: Nothing in the video presentation attached to the article proves that this theory works; at no time was a hydrodissection wave observed. I rather believe that the repeated manipulations of the nucleus with the belly of the phaco tip during the anterior cortex aspiration loosened the adhesions of the soft cortex to the posterior capsule.

$\mathrm{R}$ : Observation of the hydro-wave is not important during irrigation dynamic pressure hydrodissection $(\mathrm{iH})$ because, in contrast to the conventional manual hydrodissection that requires the use of a cannula and syringe, the $\mathrm{iH}$ technique is able to achieve the hydrodissection effect through the use of a mild irrigation pressure at multiple capsulorhexis edges. However, I do agree with the latter point made by Dr Bordeianu, as aspiration of the anterior cortex does help to loosen the cortical-capsular adhesion, thereby facilitating the irrigation flow throughout the entire cortical-capsular space.

Q: However, these forced movements of pushing/rotating the still adherent nucleus are far from the ideal phacoemulsification technique, in which the lens should not change its position in relation to the other components of the anterior pole; this is of particular importance, especially in cases with frail zonulae.

$\mathrm{R}$ : Please note that the rotation of the nucleus, which is free from the cortical-capsular connection, only occurs after the $\mathrm{iH}$ has been completed. Since we never rotate the nucleus if any adherence is present, this ensures that we are preventing excessive force on the capsule and zonulae.

Q: Overall, I believe that my technique is safer, after performing the "one drop staining technique" for the anterior capsule (an original approach) ...

R: Since we have not been able to find and read your cited manuscript or to watch any videos that document your 
surgical technique, we cannot compare the safety of the two different methods. Once we are able to access this information, we look forward to a discussion on the comparisons between these two techniques.

\section{Disclosure}

The author reports no conflicts of interest in this communication.

Dove Medical Press encourages responsible, free and frank academic debate. The content of the Clinical Ophthalmology 'letters to the editor' section does not necessarily represent the views of Dove Medical Press, its officers, agents, employees, related entities or the Clinical Ophthalmology editors. While all reasonable steps have been taken to confirm the content of each letter, Dove Medical Press accepts no liability in respect of the content of any letter, nor is it responsible for the content and accuracy of any letter to the editor.

\section{Publish your work in this journal}

Clinical Ophthalmology is an international, peer-reviewed journal covering all subspecialties within ophthalmology. Key topics include: Optometry; Visual science; Pharmacology and drug therapy in eye diseases; Basic Sciences; Primary and Secondary eye care; Patient Safety and Quality of Care Improvements. This journal is indexed on
PubMed Central and CAS, and is the official journal of The Society of Clinical Ophthalmology (SCO). The manuscript management system is completely online and includes a very quick and fair peer-review system, which is all easy to use. Visit http://www.dovepress.com/ testimonials.php to read real quotes from published authors. 